CARDIOVASCULAR MEDICINE

\title{
Short-term statin treatment improves endothelial function and neurohormonal imbalance in normocholesterolaemic patients with non-ischaemic heart failure
}

\author{
C H Strey, J M Young, J H Lainchbury, C M Frampton, M G Nicholls, A M Richards, \\ R S Scott
}

See end of article for authors' affiliations

Correspondence to: Professor Russell S Scott, Lipid and Diabetes Research, Christchurch Hospital and Christchurch School of Medicine and Health Sciences,

Christchurch, New

Zealand; russell.scott@

chmeds.ac.nz

Accepted 9 May 2006

Published Online First

18 May 2006

\begin{abstract}
Objectives: To investigate the effect of short-term statin treatment on impaired endothelium-dependent vasodilatation and haemodynamic abnormalities typically occurring in chronic heart failure (CHF).

Methods: In a double-blind, crossover study endothelium-dependent vasodilatation was measured in conduit and resistance vessels of 23 patients with non-ischaemic CHF after 6 weeks of placebo and $40 \mathrm{mg}$ atorvastatin. The haemodynamic impact was assessed by cardioendocrine hormones, echocardiography and clinical indicators of CHF.

Results: Cholesterol concentrations were population average (low density lipoprotein 3.56 (SEM $0.16) \mathrm{mmol} / \mathrm{I}$, triglycerides $1.70(0.20) \mathrm{mmol} / \mathrm{I}$ and high density lipoprotein $1.17(0.07) \mathrm{mmol} / \mathrm{l})$. In resistance vessels, the area under the curve ratio during acetylcholine infusion increased from 9.2 (1.9) with placebo to $12.2(2.1)$ with statin $(p<0.01)$. This improvement was reversed during co-infusion with the nitric oxide antagonist $N^{G}$-monomethyl-L-arginine. In conduit arteries, flow-mediated dilatation increased from 5.64 (SEM 0.88)\% with placebo to $6.83(0.97) \%$ with statin ( $p<0.05$ ). Endotheliumindependent vasodilatation did not change ( $p=0.68$ for conduit and $p=0.45$ for resistance vessels). Endothelin 1 and atrial natriuretic peptide (ANP) decreased from $1.57(0.08)$ and 51.3 (1.0) with placebo to $1.42(0.09) \mathrm{pg} / \mathrm{ml}(\mathrm{p}<0.05)$ and 42.1 (7.5) pmol// $(\mathrm{p}<0.05)$, respectively, with statin.

Conclusions: In patients with non-ischaemic CHF and population-average cholesterol concentrations, short-term statin treatment improves endothelial function in conduit and resistance vessels and lowers plasma endothelin 1 and ANP concentrations.
\end{abstract}

$\mathrm{T}$ he peripheral circulation is abnormal in chronic heart failure (CHF). ${ }^{1}$ The increase in total peripheral resistance adds to the burden of the struggling myocardium. Redistribution of arterial blood flow along with raised venous pressure compromises the functioning of various tissues and organs. Whereas it is well known that endothelial dysfunction contributes to these circulatory disturbances, ${ }^{2}$ how to reverse the underlying abnormalities is less evident.

Where coronary artery disease is present and the dominant cause of CHF, treatment with statins is logical. However, in a sizeable proportion of patients the cause of CHF is prior hypertension, idiopathic dilated cardiomyopathy or one of several other rarer disorders. In such clinical states a rational argument for benefit from statin treatment is controversial. Furthermore, concerns about potential adverse effects of statin in CHF have been raised. ${ }^{34}$

Endothelial dysfunction results from heart failure itself, irrespective of the presence of ischaemic heart disease, ${ }^{1}$ and has been recognised as a potential treatment target. ${ }^{2}$ As statins improve peripheral and coronary endothelial function through low density lipoprotein (LDL) lowering and pleiotropic mechanisms, ${ }^{56}$ we hypothesised that treatment with a statin would improve haemodynamic abnormalities in patients with cardiac failure even in the absence of underlying coronary artery disease. Accordingly we studied the effects of atorvastatin on endothelial function in patients with CHF in a double-blind, placebo-controlled crossover study. Presuming that any statin-induced improvement in the regulation of peripheral circulation can be reflected by changes in central haemodynamic function, we measured plasma concentrations of the cardiac natriuretic peptides and echocardiographic indices of cardiac structure and function.

\section{METHODS}

Twenty-four patients were recruited from the Cardiology Department outpatient clinic at Christchurch Hospital. All had symptomatic heart failure (New York Heart Association functional class II or III) and a reduced left ventricular ejection fraction $(<40 \%)$ on echocardiography. They were all receiving standard heart failure treatment with a loop diuretic, plus an angiotensin-converting enzyme inhibitor or angiotensin II receptor antagonist with or without digoxin, a $\beta$ adrenergic blocker and spironolactone in unchanged dosage for at least three months before enrolment. No patient was in atrial fibrillation or was receiving lipidmodifying drugs, or had experienced a prior acute coronary event or revascularisation procedure. None had stenotic cardiac valve disease, impaired liver function, a glomerular filtration rate of $<100 \mathrm{ml} / \mathrm{min}$ (as calculated by the Cockcroft and Gault formula) or reduced pulmonary function (forced expiratory volume in $1 \mathrm{~s}$ of $<1$ litre). The study size $(\mathrm{n}=24)$ was determined from reported effects of statins on endothelial function under other clinical circumstances ${ }^{56}$ and

Abbreviations: ANP, atrial natriuretic peptide; BNP, B-type natriuretic peptide; $\mathrm{CHF}$, chronic heart failure; CNP, C-type natriuretic peptide; $\mathrm{CV}$, coefficient of variation; EID, endothelium-independent dilatation; FMD, flow-mediated dilatation; LDL, low density lipoprotein; L-NMMA, $N^{G}$ monomethyl---arginine; NO, nitric oxide 
assumed an increase in endothelium-dependent blood flow by $30 \%$ with a standard deviation of $20 \%^{7}$ at $p<0.05$ with a power of $80 \%$. Informed, written consent was obtained from every participant. The Ethics Committee of Canterbury Health Limited approved the study protocol, which complied with the Declaration of Helsinki.

\section{Study protocol}

All patients received atorvastatin $40 \mathrm{mg}$ or placebo once daily in the evening for six weeks in a randomised, placebocontrolled, double-blind crossover study. The crossover design was chosen to minimise interindividual variability. Between treatments there was a two-week washout period. Statin has been shown to reversibly improve endothelial function within two weeks in conduit ${ }^{8}$ and resistance vessels. ${ }^{9}$ All heart failure drugs were required to be continued in unchanged dosage for the duration of the study and the prior three months. After the six-week treatment with statin or placebo, patients attended the research centre at 0730 after fasting overnight for a set sequence of tests: brachial ultrasound, venepuncture, forearm plethysmography, 6 min walk test, ${ }^{10}$ echocardiography and the Minnesota Living with Heart Failure Quality of Life Questionnaire. ${ }^{11}$ All tests were carried out in a quiet, air-conditioned room with a stable temperature of $22^{\circ} \mathrm{C}$, with the exception of the 6 min walk, which took place in a designated hospital corridor.

\section{Brachial ultrasound}

Conduit artery function was assessed by brachial ultrasound based on the protocol described by Celermajer et al. ${ }^{12}$ The assessment adhered to guidelines published by the International Brachial Reactivity Task Force ${ }^{13}$ and used a fully digitised ultrasound system (Logiq 700 Expert Series; GE Medical Systems) with a high-resolution, broad-spectrum transducer (6-13 MHz, LA39; GE Medical Systems). Briefly, the participant was kept in a recumbent position for $15 \mathrm{~min}$ before measurements were started, with the non-dominant arm being held in a specially designed cradle and the ultrasound transducer fixed in position with a stereotactic clamp. The brachial artery was imaged in the longitudinal plane during the baseline resting phase, after $5 \mathrm{~min}$ of forearm ischaemia to assess endothelium-dependent flowmediated dilatation (FMD) and after $800 \mathrm{~g}$ sublingual glyceryl trinitrate was given to assess endothelium-independent dilatation (EID). Recordings were made only when welldefined, double-line patterns ${ }^{14}$ were present proximally and distally throughout the entire area of interest. Measurements from fixed anatomical landmarks eliminated positional variations between study visits. All recordings were made by the same investigator and frame analyses were completed before unblinding of the study drug sequence. Scans were recorded on sVHS tapes and digitised (Pinnacle DV500 Plus; Pinnacle Systems). Diastolic frames were identified by gating simultaneously recorded Doppler curves and were measured frame by frame with specially developed edge detection software. Vessel diameter was defined as the distance between the distal and proximal lumen-intima interface. FMD and EID were expressed as the percentage increase of vessel diameter from baseline-that is, [(maximum diameter after ischaemia or glyceryl trinitrate administration - baseline diameter)/baseline diameter $] \times 100$. The coefficient of variation (CV) was 3\% for measurement of baseline diameters, $22 \%$ for FMD and $11 \%$ for EID.

\section{Forearm strain gauge plethysmography}

Resistance vessel function was assessed by invasive venous occlusion plethysmography (Hokanson, Bellevue, Washington, USA) based on the protocol described by Watts et al. ${ }^{15}$ The brachial artery in the non-dominant arm was cannulated with a 27 gauge needle. Blood flow was measured after the following intra-arterial infusions: (A) $0.9 \%$ saline for $30 \mathrm{~min}$ (baseline); (B) acetylcholine at 7.5, 15 and $30 \mathrm{~g} / \mathrm{min}$ for $3 \mathrm{~min}$ each; (C) sodium nitroprusside at 1.5, 3.0 and $10 \mathrm{~g} / \mathrm{min}$ for $3 \mathrm{~min}$ each; and (D) $N^{\mathrm{G}}$ monomethyl-L-arginine (L-NMMA) (Clinalfa AG, Kilsyth, Victoria, Australia) at $4.0 \mathrm{~g} / \mathrm{min}$ alone and co-infused with each incremental acetylcholine infusion for $3 \mathrm{~min}$ each. There was a break of $15 \mathrm{~min}$ between different infusions during which the saline infusion continued. Control blood flow was measured in the dominant (non-infused) arm. The forearm was distended by inflating and deflating brachial cuffs to supravenous pressure levels (45 mm $\mathrm{Hg}$ ) with a rapid cuff inflator (E20; Hokanson) for 5 and $10 \mathrm{~s}$, respectively. Ten inflation-deflation cycles were recorded for each stage of the protocol and results were averaged. Forearm blood flow was expressed as the area under the curve according to the trapezoid rule, by using specially developed software. To correct for systemic changes the ratio between the area under the curve in the infused and the noninfused arm was calculated. ${ }^{16}$ The intraobserver (between weeks) CV for this method was $19 \%$ in the resting state and $17 \%$ after 5 min of ischaemia.

\section{Biochemical markers}

Venous blood was drawn from a forearm vein at the conclusion of the brachial artery ultrasound study after the patients had been supine for $45 \mathrm{~min}$, just before arterial cannulation, for measurements of plasma atrial natriuretic peptide (ANP), ${ }^{17}$ B-type natriuretic peptide ${ }^{18}$ (BNP), Nterminal $\mathrm{BNP},{ }^{19}$ the endothelial markers $\mathrm{C}$-type natriuretic peptide (CNP), $\mathrm{N}$-terminal $\mathrm{CNP}^{20}$ endothelin $1,{ }^{21}$ vascular cell adhesion molecule l (R\&D Systems, Minneapolis, Minnesota, USA; enzyme-linked immunosorbent assay intra-assay CV 5\%) and von Willebrand factor, adrenomedullin, ${ }^{22}$ aldosterone, ${ }^{22}$ epinephrine and norepinephrine. ${ }^{23}$ All samples from an individual patient were measured in the same assay. Intra-assay and interassay CV varied between $5 \%$ and $9 \%$ for these tests. Also measured were plasma lipid concentrations, high-sensitivity $\mathrm{C}$ reactive protein, fibrinogen, plasma glucose, urea, creatinine and liver function.

\section{Echocardiography}

Transthoracic echocardiographic examinations were performed with a Vivid 3 echocardiograph (General Electric, Fairfield, Connecticut, USA) by a single operator who was blinded as to the treatment phase, with participants in the left lateral decubitus position. M mode echocardiographic variables were measured according to the recommendations of the American Society of Echocardiography. ${ }^{24}$ Left ventricular mass was calculated with the formula derived from the American Society of Echocardiography data. ${ }^{25}$ Left ventricular ejection fraction was calculated by the biplane disc summation method. ${ }^{26}$ The average of three measurements was used for all variables.

\section{Statistical analysis}

Statistical calculations were performed with SPSS Base V.10.0 (SPSS, Inc, Chicago, Illinois, USA). The paired t test or Wilcoxon signed rank test was used for comparisons between placebo and statin groups. The treatment effect on resistance vessel function during drug infusion was analysed by repeated measures analysis of variance (general linear model). The influence of the treatment sequence and the severity of heart failure on statin-induced changes were analysed with repeated measures analysis of variance by using the in-between group function. If influences were found, respective subgroups were analysed for the difference of the mean by the independent $t$ test or Mann-Whitney $U$ 
Table 1 Baseline characteristics of study participants

\begin{tabular}{|c|c|}
\hline Total number of participants & $23^{*}$ \\
\hline Age (years) & $60.7(10.4)$ \\
\hline Men/women & $16 / 7$ \\
\hline Smokers & 3 \\
\hline NYHA class II/III & $14 / 9$ \\
\hline LVEF (\%) & $30.1(7.7)$ \\
\hline Time from first diagnosis (months) & $46.7(54.6)$ \\
\hline Normal coronary angiogram & $15+$ \\
\hline Abnormal coronary angiogram & $4 \S$ \\
\hline Type 2 diabetes & 4 \\
\hline Hypertension & 8 \\
\hline Body mass index $\left(\mathrm{kg} / \mathrm{m}^{2}\right)$ & $27.2(4.9)$ \\
\hline Systolic blood pressure $(\mathrm{mm} \mathrm{Hg})$ & $120.8(16.5)$ \\
\hline Diastolic blood pressure (mm Hg) & $77.8(8.9)$ \\
\hline MAP $(\mathrm{mm} \mathrm{Hg})$ & $92.1(11.1)$ \\
\hline Serum urea $(\mathrm{mmol} / \mathrm{l})$ & $7.5(3.0)$ \\
\hline Serum creatinine $(\mathrm{mol} / \mathrm{l})$ & $0.09(0.02)$ \\
\hline Plasma glucose (mmol/l) & $5.5(2.5)$ \\
\hline Serum GGT (mmol/l) & $47.9(63.3)$ \\
\hline Serum AST (mmol/l) & $23.5(7.4)$ \\
\hline hsCRP (mg/l) & $2.02(0.33)$ \\
\hline Fibrinogen (g/l) & $3.3(0.1)$ \\
\hline UACR $(\mathrm{g} / \mathrm{mol})$ & $0.95(0.12)$ \\
\hline \multicolumn{2}{|l|}{ Concomitant drugs } \\
\hline Furosemide & 18 \\
\hline Furosemide dose (mg/day) & $142.2(341.5)$ \\
\hline Enalapril or equivalent & 18 \\
\hline Enalapril dose (mg/day) & $13.9(7.4)$ \\
\hline ATIIRB & 4 \\
\hline$\beta$ blocker & 13 \\
\hline Digitalis & 2 \\
\hline Spironolactone & 4 \\
\hline Aspirin & 14 \\
\hline Aspirin dose (mg/day) & $167.9(75.0)$ \\
\hline \multicolumn{2}{|c|}{$\begin{array}{l}\text { Data presented as mean (SD) or number. } \\
\text { *Heart failure causes: idiopathic (12), hypertension (4), viral } \\
\text { (4), familial (2), myotonic dystrophy (1), Marfan's syndrome } \\
\text { (1); †coronary angiogram not performed in four participants } \\
\text { with a low probability of ischaemic heart disease; fsome } \\
\text { degree of coronary artery disease in patients without angina } \\
\text { pectoris and normal thallium and sestamibi stress test. } \\
\text { AST, aspartate amino transferase; ATIIRB, angiotensin II } \\
\text { receptor blocker; GGT, } \gamma \text { glutamyl transferase; hsCRP, high } \\
\text { sensitivity C reactive protein; LVEF, left ventricular ejection } \\
\text { fraction; MAP, mean arterial blood pressure; NYHA, New } \\
\text { York Heart Association; UACR, urinary albumin creatinine } \\
\text { ratio. }\end{array}$} \\
\hline
\end{tabular}

test. Correlation was analysed with Pearson's or Spearman's correlation coefficient. Significance was accepted at the 95\% confidence interval $(\mathrm{p}<0.05)$.

LDL cholesterol and triglycerides were reduced by $50 \%$ and $32 \%$. High density lipoprotein cholesterol remained unchanged.

\section{RESULTS}

Twenty-three patients completed the study, as one was excluded with worsening heart failure necessitating alteration of drugs. One patient with myotonic dystrophy developed mild proximal myalgia without a rise in muscle enzymes. Compliance rates based on tablet counts were 97\% during placebo administration and 98\% during statin treatment.

\section{Baseline characteristics}

Table 1 snows baseline characteristics of the patients.

Nineteen patients underwent coronary angiography; 15 of the angiograms were normal and four had some features of atherosclerotic disease in patients with no symptoms of myocardial ischaemia and normal thallium and sestamibi stress tests. The four remaining participants with a low probability of ischaemic cardiomyopathy in the absence of cardiovascular risk factors (39-60 years of age, non-smokers, no dyslipidaemia, no family history, no hypertension and no obesity) and without symptoms or signs of myocardial ischaemia did not undergo coronary angiography. Table 2 shows the placebo and statin effects on lipid parameters.

\section{Endothelial function}

Table 3 summarises conduit vessel function after administration of the statin and placebo.

Compared with placebo, statin was associated with significantly greater endothelium-dependent dilatation (FMD), but not EID. Figures $1-3$ show forearm resistance vessel function during infusion of acetylcholine, sodium nitroprusside and L-NMMA alone or in combination with acetylcholine after statin and placebo administration. After statin treatment, endothelium-dependent vasodilatation during acetylcholine infusion was significantly greater than after placebo administration for the two highest infusion rates and

\begin{tabular}{|c|c|c|c|}
\hline & Placebo & Statin treatment & p Value \\
\hline \multicolumn{4}{|l|}{ Cholesterol } \\
\hline Total (mmol/l) & $5.50(0.21)$ & $3.47(0.15)$ & $<0.001$ \\
\hline $\mathrm{LDL}(\mathrm{mmol} / \mathrm{l})$ & $3.56(0.16)$ & $1.77(0.11)$ & $<0.001$ \\
\hline $\mathrm{HDL}(\mathrm{mmol} / \mathrm{l})$ & $1.17(0.07)$ & $1.18(0.07)$ & 0.55 \\
\hline Triglycerides (mmol/l) & $1.70(0.20)$ & $1.15(0.09)$ & $<0.001$ \\
\hline \multicolumn{4}{|l|}{ Endothelial markers } \\
\hline vWF (\%) & $126.14(6.01)$ & $125.45(6.40)$ & 0.89 \\
\hline VCAM-1 (ng/ml) & $584(25)$ & $568(28)$ & 0.24 \\
\hline Endothelin 1 (pg/ml) & $1.57(0.08)$ & $1.42(0.09)$ & $<0.05$ \\
\hline CNP (pmol/l) & $1.06(0.05)$ & $0.99(0.05)$ & 0.08 \\
\hline \multicolumn{4}{|l|}{ Cardioendocrine hormones } \\
\hline ANP (pmol/l) & $51.25(9.98)$ & $42.05(7.47)$ & $<0.05$ \\
\hline $\mathrm{BNP}(\mathrm{pmol} / \mathrm{l})$ & $25.98(4.35)$ & $21.56(3.67)$ & 0.19 \\
\hline N-BNP (pmol/l) & $135.17(24.73)$ & $116.05(22.10)$ & 0.11 \\
\hline Adrenomedullin (pmol/l) & $8.86(0.70)$ & $8.26(0.55)$ & 0.20 \\
\hline Epinephrine (pmol/l) & $96.20(21.56)$ & $91.82(15.79)$ & 0.56 \\
\hline Norepinephrine (pmol/l) & 3123.57 (391.39) & $2889.04(245.52)$ & 0.43 \\
\hline
\end{tabular}

Data presented as mean (SEM)

ANP, atrial natriuretic peptide; BNP, B-type natriuretic peptide; CNP, C-type natriuretic peptide; HDL, high density lipoprotein; LDL, low density lipoprotein; N-BNP, N-terminal B-type natriuretic peptide; UACR, urinary albumin creatinine ratio; VCAM, vascular cell adhesion molecule; vWF, von Willebrand factor. 
Table 3 Brachial artery function after placebo and statin administration

\begin{tabular}{lllc}
\hline & Placebo & Statin treatment & p Value \\
\hline Pulse rate (beats/min) & $70.5(3.0)$ & $69.2(2.9)$ & 0.34 \\
Mean arterial blood pressure (mm Hg) & $90.1(2.3)$ & $90.2(2.1)$ & 0.93 \\
Baseline blood flow (ml/min) & $66.6(3.9)$ & $67.5(3.1)$ & 0.76 \\
Peak hyperaemic flow (ml/min) & $138.1(7.9)$ & $147.9(9.6)$ & 0.30 \\
Baseline diameter (mm) & $3.57(1.59)$ & $3.60(1.60)$ & 0.49 \\
Maximum hyperaemic diameter (mm) & $3.75(0.15)$ & $3.83(1.60)$ & 0.12 \\
Flow-mediated dilatation (\%) & $5.64(0.88)$ & $6.83(0.97)$ & $<0.05$ \\
Endothelium-independent dilatation (\%) & $21.69(2.94)$ & $20.87(2.73)$ & 0.68 \\
\hline Data presented as mean (SEM). & & \\
\hline
\end{tabular}

when all infusion rates were analysed collectively (fig l). This difference was obliterated during co-infusion with the nitric oxide (NO) antagonist L-NMMA (fig 3). Nitroprussideinduced vasodilatation was similar after statin and placebo $(\mathrm{p}=0.45)$ (fig 2). Mean blood pressure did not vary significantly between blood flow studies.

\section{Endothelial markers and cardioendocrine hormones}

All endothelial markers and cardioendocrine hormones measured in this study (table 2) were lower after six-week treatment with statin than after placebo; however, this reached significance only for plasma concentrations of endothelin 1 and ANP. After both treatments $\gamma$ glutamyl transferase, aspartate transferase and creatine kinase were similar (data not shown). Treatments did not differ in clinical measurements of heart failure (table 4).

\section{Correlations and multivariate analysis}

CNP and adrenomedullin were inversely correlated with endothelium-dependent vasodilatation during acetylcholine infusion (with statin $\mathrm{r}=-0.606, \mathrm{p}<0.01$ and $\mathrm{r}=-0.517, \mathrm{p}<0.05$; with placebo $\mathrm{r}=-0.489, \mathrm{p}<0.05$ and $\mathrm{r}=-0.581, \mathrm{p}<0.05$, respectively). The endothelial makers CNP and N-terminal CNP correlated with systolic internal dimensions (with statin $r=0.486, p<0.05$ and $r=0.367, p=0.111$; with placebo $r=0.430, p=0.058$ and $\mathrm{r}=0.583, \mathrm{p}<0.01)$ and diastolic internal dimensions (with statin $\mathrm{r}=0.682, \mathrm{p}<0.001$ and $\mathrm{r}=0.494, \mathrm{p}<0.05$; with placebo $r=0.483, \mathrm{p}<0.05$ and $\mathrm{r}=0.595, \mathrm{p}<0.01)$. Echocardiographic indices and lipoprotein fractions (specified in table 2) did not correlate with endothelium-dependent responses in either forearm vessels or the brachial artery before or after statin treatment. Multivariate tests showed no

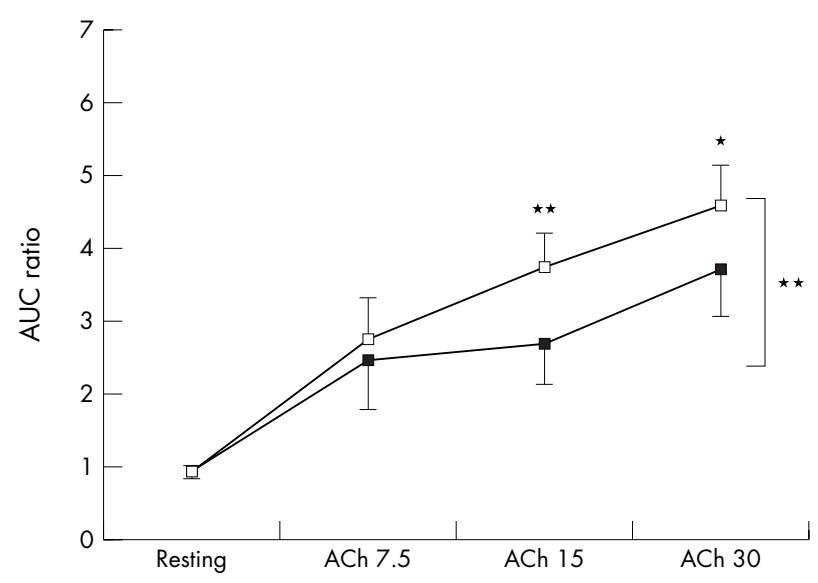

Figure 1 Effect of intra-arterial acetylcholine ( $\mathrm{ACh} ; 7.5-30 \mu \mathrm{g} / \mathrm{min}$ ) on forearm blood flow after placebo (black squares) and statin (white squares) application for six weeks. Data presented as mean (SEM). ${ }^{*} p=0.07 ;{ }^{* *} p \leqslant 0.01$. AUC, area under the curve.

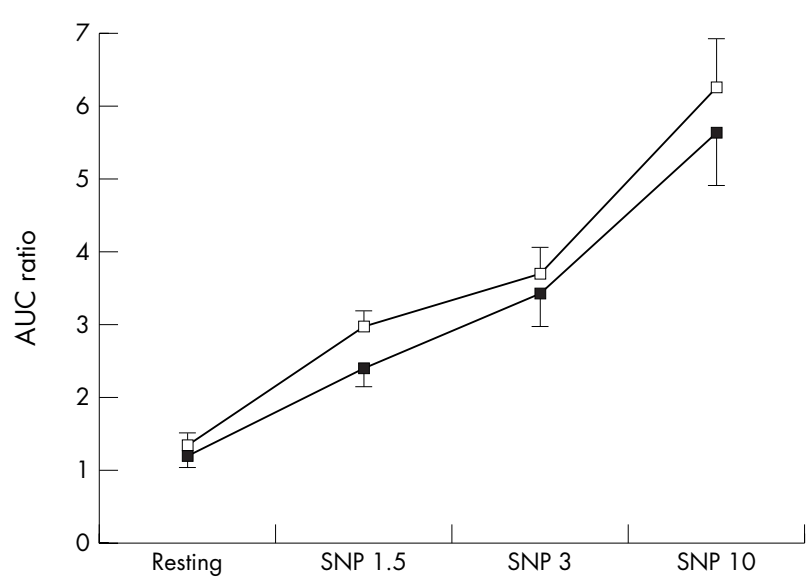

Figure 2 Effect of intra-arterial sodium nitroprusside (SNP; 1.5-10 $\mu \mathrm{g} /$ $\mathrm{min}$ ) infusion on forearm blood flow after placebo (black squares) and after statin (white squares) administration for six weeks. Data presented as mean (SEM). AUC, area under the curve.

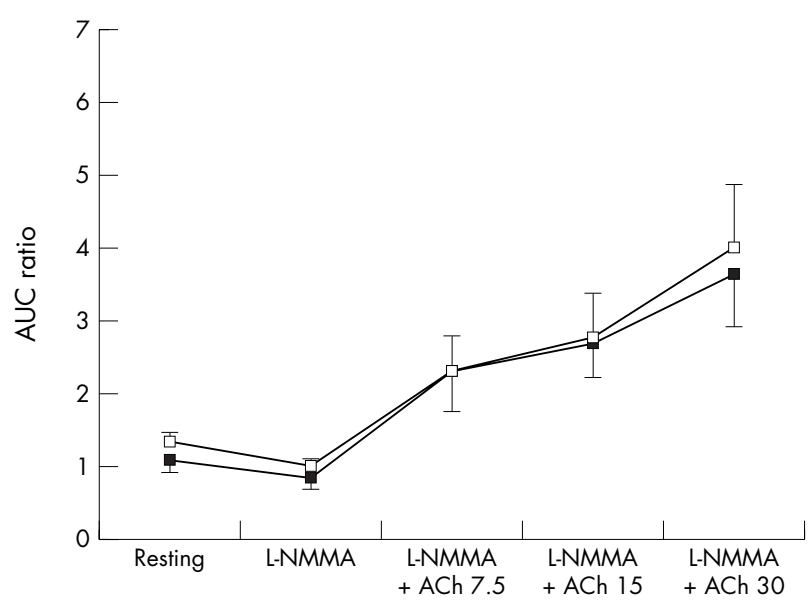

Figure 3 Effect of intra-arterial infusion of $N^{G}$-monomethyl-L-arginine (L-NMMA) alone and in combination with acetylcholine (ACh; 7.5-30 $\mu \mathrm{g} / \mathrm{min}$ ) on forearm blood flow after placebo (black squares) and after statin (white squares) administration for six weeks. Data presented as mean (SEM). AUC, area under the curve.

significant influence of the functional heart failure class or the treatment order on endothelium-dependent conduit or resistance vessel function.

\section{DISCUSSION}

Our findings suggest that in patients with non-ischaemic heart failure short-term statin treatment is associated with improvements in endothelium-dependent vasodilatation in conduit and resistance vessels. We showed endothelial NO 
Table 4 Clinical measurements of heart failure after placebo and statin administration

\begin{tabular}{llll}
\hline & Placebo & Statin treatment & p Value \\
\hline Internal dimension in diastole (mm) & $68.0(2.5)$ & $67.0(2.6)$ & 0.41 \\
Internal dimension in systole (mm) & $59.1(2.7)$ & $56.6(3.6)$ & 0.20 \\
Left ventricular ejection fraction (\%) & $29.7(2.3)$ & $31.0(2.4)$ & 0.59 \\
Peak early diastolic transmitral flow velocity (cm/s) & $76.4(7.6)$ & $76.8(8.1)$ & 0.37 \\
Peak transmitral flow velocity with atrial contraction (cm/s) & $83.4(4.8)$ & $76.6(4.3)$ & 0.20 \\
Deceleration time (ms) & $224.5(26.8)$ & $204.5(18.3)$ & 0.37 \\
Left ventricular mass (g) & $273.9(23.5)$ & $306.0(32.1)$ & 0.25 \\
6 min walking test (m) & $466.2(18.9)$ & $471.9(20.2)$ & 0.44 \\
MLHFQL questionnaire score & $28.5(4.6)$ & $29.9(4.5)$ & 0.63 \\
\hline Data presented as mean (SEM). & & & \\
MLHFQL, Minnesota Living with Heart Failure Quality of Life. & & \\
\end{tabular}

dependence of statin-associated benefits in resistance vessels, as augmentation was seen only during NO-stimulating acetylcholine infusion and reversed during co-infusion of the NO-blocking L-NMMA. Nitroprusside-induced, endothelium-independent resistance vessel function was not augmented during statin treatment. Two comparable studies did not obtain statin-induced improvements of resistance vessel function. ${ }^{27} 28$ In both of these studies non-invasive plethysmography was used to assess resistance vessel function after ischaemia, a technique with a low specificity for endothelial function. ${ }^{29}$ In conduit vessels, our findings of improved endothelial function concur with the results of a study by Node $e t a l^{30}$ in patients with idiopathic dilated cardiomyopathy also reporting FMD augmentation after 14 weeks of statin treatment. The more pronounced FMD improvement (from $8 \%$ to $13 \%$ ) in this study may be due to the longer treatment period.

The endothelium-specific benefits seen during statin treatment may be largely LDL cholesterol independent. Our participants exhibited serum LDL cholesterol concentrations below population average, a finding typical for CHF. Furthermore, neither absolute LDL cholesterol concentrations nor LDL cholesterol reductions determined the degree of endothelial amelioration. Cholesterol-independent or pleiotropic statin effects have long been postulated, ${ }^{31}$ recently gaining more widespread recognition. ${ }^{32} 33$ Pleiotropic statin effects contribute to the reversal of two main pathogenic mechanisms leading to impaired vasodilatation in CHF: decreased vasodilating $\mathrm{NO}$ and increased vasoconstricting endothelin $1 .^{34}$ Independent of LDL cholesterol reduction, statins upregulate and promote endothelial NO synthase ${ }^{35} 36$ and reduce endothelin 1 expression in endothelial cells. ${ }^{37}$ Compelling evidence that statin-induced endothelial benefits in CHF are pleiotropic derives from a recent study by Landmesser et al, ${ }^{38}$ who reported FMD reductions in patients with CHF taking statins, but not with ezetimibe, despite almost identical LDL cholesterol reductions. It should be noted, however, that in this study ischaemic CHF was not an exclusion criterion.

In our study, treatment with a statin versus placebo was associated with lower concentrations of all measured cardioendocrine hormones, although the difference was significant only for ANP. Given the problems with cardioendocrine hormone measurement and the small patient population examined, the data are suggestive of statinderived benefits for the CHF typical neurohormonal imbalance. One other clinical study investigated the effect of statin on cardioendocrine hormones in non-ischaemic $\mathrm{CHF}^{30}$ and reported BNP reductions. It is uncertain whether the stabilisation of the neurohormonal imbalance is secondary to improvements in endothelial dysfunction or to other statin effects with the potential to delay CHF progression. Such effects include the induction of neoangiogenesis, the downregulation of angiotensin II type 1 receptors, the restoration of autonomic dysfunction and the inhibition of proinflammatory cytokines. ${ }^{4}$ The absence of clear correlations between improvements in endothelium-dependent vasodilatation and cardioendocrine hormone reductions in our study may emphasise direct, cardioprotective effects. However, endothelium-ameliorating and other cardioprotective statin effects probably act synergistically.

After six weeks of statin treatment, improvements in endothelial dysfunction and cardioendocrine imbalance had no measurable effect on clinical CHF indices. Longer treatment intervals are likely to yield measurable clinical benefits, however, considering the findings of two comparable studies that ejection fractions and quality of life scores improved after treatment intervals twice to thrice as long as in our study, despite lower dose equivalents. ${ }^{27} 30$

The coupling of endothelial and cardiac function can be illustrated by focusing on the endothelial hormones endothelin 1 and CNP. Blocking endothelin 1 , excreted by the dysfunctional endothelium ${ }^{39}$ and typically raised in heart failure, ${ }^{40}$ with the endothelin receptor antagonist bosentan reduces ANP and BNP in sheep, ${ }^{41}$ stressing the concept that endothelial recovery may ameliorate neurohormonal imbalance. Statins decrease the endothelial synthesis of endothelin 1 in vitro $^{37}$ and we showed this effect for the first time in patients with non-ischaemic CHF without other major, endothelium-harming conditions. CNP is considered a member of the natriuretic peptide family and structurally homologous to ANP and BNP, ${ }^{42}$ but is the only natriuretic peptide produced mainly in vascular endothelial cells ${ }^{43}$ and expressed proportional to endothelial stress. ${ }^{44}$ CNP may therefore be an important endothelial mediator of the haemodynamic disturbances found in CHF. In our study CNP reductions did not reach significance $(p=0.08)$. This is nevertheless remarkable, as peripheral plasma concentrations of CNP are close to assay detection limits and only minimally raised in heart failure, ${ }^{45}$ perhaps acting primarily in a paracrine fashion.

Statin treatment may potentially be unfavourable in patients with CHF. Lipoprotein reductions may negate statin-specific pleiotropic benefits in CHF. ${ }^{3}$ Low cholesterol concentrations have been related to impaired survival from heart failure. ${ }^{46}$ Furthermore, statin treatment is associated with coenzyme $\mathrm{Q}_{10}$ reductions, ${ }^{47}$ which have been correlated with the severity of $\mathrm{CHF}^{48}$ However, the cause-effect relationship of these observations has not been determined and we recently found that the beneficial effects of statin treatment on endothelium-dependent vasodilatation in CHF are strongly associated with reductions in coenzyme $\mathrm{Q}_{10} \cdot{ }^{49}$

\section{Study limitations}

Our study may have been underpowered, especially for highly variable measures such as cardioendocrine hormones or flowmediated brachial artery vasodilatation. The recorded improvements are subtle yet, if taken together, are consistent 
for statin-associated benefits. In the absence of baseline data immediately before each treatment period, we are unable to exclude the influence of a time effect on our findings. However, the short-term crossover design should have kept a time effect bias minimal. Focusing on patients with nonischaemic cardiomyopathy, we were unable to entirely exclude a potential component of ischaemic cardiomyopathy in eight participants.

\section{Clinical significance}

We showed for the first time that patients with nonischaemic heart failure have better endothelium-dependent vasodilatation in resistance vessels and lower plasma endothelin 1 and ANP concentrations while being treated with a statin than when given a placebo. These benefits were detectable after only six weeks in participants already treated with endothelial and cardiac function-ameliorating drugs. These benefits may translate into increased exercise capacity and improved peripheral perfusion when statins are given over longer time periods. ${ }^{2}$ Recent cohort studies show improved survival ${ }^{50-53}$ of patients with heart failure treated with statins. Our findings further strengthen the notion of using statins in heart failure regardless of its aetiology and in the absence of dyslipidaemia. However, the routine use of statins by patient with heart failure due to other causes than coronary artery disease can not be recommended while randomised controlled trials determining benefits versus risks are awaited.

\section{Conclusions}

Adding a statin to the treatment regimen of patients with CHF, optimised with standard treatment, results in improved endothelium-dependent vasodilatation, reduced plasma endothelin 1 and ANP, and an overall trend for reduced cardioendocrine stress. These differences from placebo were present after six weeks of statin treatment in patients with non-ischaemic CHF and below population-average LDL concentrations.

\section{ACKNOWLEDGEMENTS}

We thank Mr Sinclair Bennett for developing blood flow analysis software and Christchurch Hospital Pharmacy staff for preparing intra-arterial infusions.

\section{Authors' affiliations}

C H Strey, Department of Endocrinology, Addenbrooke's Hospital, Cambridge University Hospitals, Cambridge, UK

J M Young, J H Lainchbury, C M Frampton, A M Richards, R S Scott, Lipid and Diabetes Research and Department of Medicine, Christchurch Hospital and Christchurch School of Medicine and Health Sciences, Christchurch, New Zealand

M G Nicholls, Department of Internal Medicine, Faculty of Medicine and Health Sciences, United Arab Emirates University, Al Ain, United Arab Emirates

This study was funded entirely by a grant from the Health Research Council of New Zealand.

Competing interests: None declared.

\section{REFERENCES}

1 Kubo SH, Rector TS, Bank AJ, et al. Endothelium-dependent vasodilation is attenuated in patients with heart failure. Circulation 1991;84:1589-96.

2 Drexler H. Endothelium as a therapeutic target in heart failure. Circulation 1998;98:2652-5.

3 Rauchhaus M, Coats AJ, Anker SD. The endotoxin-lipoprotein hypothesis. Lancet 2000;356:930-3.

$4 \mathrm{Krum} \mathrm{H}, \mathrm{McMurray} \mathrm{JJ}$. Statins and chronic heart failure: do we need a largescale outcome trial? J Am Coll Cardiol 2002;39:1567-73.

5 O'Driscoll G, Green D, Taylor RR. Simvastatin, an HMG-coenzyme A reductase inhibitor, improves endothelial function within 1 month. Circulation 1997:95:1126-31.
6 Vogel RA, Corretti MC, Plotnick GD. Changes in flow-mediated brachial artery vasoactivity with lowering of desirable cholesterol levels in healthy middle-aged men. Am J Cardiol 1996;77:37-40.

7 Vogel RA. Cholesterol lowering and endothelial function. Am J Med 1999;107:479-87.

8 Marchesi S, Lupattelli G, Siepi D, et al. Short-term atorvastatin treatment improves endothelial function in hypercholesterolemic women. J Cardiovasc Pharmacol 2000;36:617-21.

9 John S, Delles C, Jacobi J, et al. Rapid improvement of nitric oxide bioavailability after lipid-lowering therapy with cerivastatin within two weeks. J Am Coll Cardiol 2001;37:1351-8.

10 Willenheimer R, Erhardt LR. Value of 6-min-walk test for assessment of severity and prognosis of heart failure. Lancet 2000;355:515-6.

11 Rector TS, Cohn JN. Assessment of patient outcome with the Minnesota Living with Heart Failure questionnaire: reliability and validity during a randomized, double-blind, placebo-controlled trial of pimobendan. Pimobendan Multicenter Research Group. Am Heart J 1992;124:1017-25.

12 Celermajer DS, Sorensen KE, Gooch VM, et al. Non-invasive detection of endothelial dysfunction in children and adults at risk of atherosclerosis. Lancet 1992;340:1111-5.

13 Corretti MC, Anderson TJ, Benjamin EJ, et al. Guidelines for the ultrasound assessment of endothelial-dependent flow-mediated vasodilation of the brachial artery: a report of the International Brachial Artery Reactivity Task Force. J Am Coll Cardiol 2002;39:257-65.

14 Pignoli P, Tremoli E, Poli A, et al. Intimal plus medial thickness of the arterial wall: a direct measurement with ultrasound imaging. Circulation 1986;74:1399-406.

15 Watts GF, O'Brien SF, Silvester W, et al. Impaired endothelium-dependent and independent dilatation of forearm resistance arteries in men with diettreated non-insulin-dependent diabetes: role of dyslipidaemia. Clin Sci (Lond) 1996;91:567-73

16 Benjamin N, Calver A, Collier J, et al. Measuring forearm blood flow and interpreting the responses to drugs and mediators. Hypertension 1995;25:918-23.

17 Yandle TG, Espiner EA, Nicholls MG, et al. Radioimmunoassay and characterization of atrial natriuretic peptide in human plasma. J Clin Endocrinol Metab 1986:63:72-9.

18 Yandle TG, Richards AM, Gilbert A, et al. Assay of brain natriuretic peptide (BNP) in human plasma: evidence for high molecular weight BNP as a major plasma component in heart failure. J Clin Endocrinol Metab 1993;76:832-8.

19 Davis M, Espiner E, Richards G, et al. Plasma brain natriuretic peptide in assessment of acute dyspnoea. Lancet 1994;343:440-4.

20 Wright SP, Prickett TC, Doughty RN, et al. Amino-terminal pro-C-type natriuretic peptide in heart failure. Hypertension 2004:43:94-100.

21 Evans JJ, Youssef AH, Yandle TG, et al. Effects of endothelin-1 on release of adrenomedullin and C-type natriuretic peptide from individual human vascular endothelial cells. J Endocrinol 2002;175:225-32.

22 Lewis LK, Smith MW, Yandle TG, et al. Adrenomedullin(1-52) measured in human plasma by radioimmunoassay: plasma concentration, adsorption, and storage. Clin Chem 1998;44:571-7.

23 Goldstein DS, Feuerstein G, Izzo JL Jr, et al. Validity and reliability of liquid chromatography with electrochemical detection for measuring plasma levels of norepinephrine and epinephrine in man. Life Sci 1981;28:467-75.

24 Sahn DJ, DeMaria A, Kisslo J, et al. Recommendations regarding quantitation in M-mode echocardiography: results of a survey of echocardiographic measurements. Circulation 1978;58:1072-83.

25 Devereux RB, Alonso DR, Lutas EM, et al. Echocardiographic assessment of left ventricular hypertrophy: comparison to necropsy findings. Am J Cardiol 1986;57:450-8

26 Schiller NB, Acquatella $H$, Ports TA, et al. Left ventricular volume from paired biplane two-dimensional echocardiography. Circulation 1979;60:547-55.

27 Laufs U, Wassmann S, Schackmann S, et al. Beneficial effects of statins in patients with non-ischemic heart failure. Z Kardiol 2004;93:103-8.

28 Tousoulis D, Antoniades C, Bosinakou E, et al. Effects of atorvastatin on reactive hyperaemia and the thrombosis-fibrinolysis system in patients with heart failure. Heart 2005;91:27-31.

29 Engelke KA, Halliwill JR, Proctor DN, et al. Contribution of nitric oxide and prostaglandins to reactive hyperemia in human forearm. J Appl Physiol 1996:81:1807-14.

30 Node K, Fujita $M$, Kitakaze $M$, et al. Short-term statin therapy improves cardiac function and symptoms in patients with idiopathic dilated cardiomyopathy. Circulation 2003;108:839-43

31 Vaughan CJ, Murphy MB, Buckley BM. Statins do more than just lower cholesterol. Lancet 1996;348:1079-82.

32 Davidson MH. Clinical significance of statin pleiotropic effects: hypotheses versus evidence. Circulation 2005;111:2280-1

33 Davignon J. Beneficial cardiovascular pleiotropic effects of statins. Circulation 2004; 109: III39-43.

34 Von Haehling S, Anker SD, Bassenge E. Statins and the role of nitric oxide in chronic heart failure. Heart Fail Rev 2003;8:99-106.

35 Laufs U, La Fata V, Plutzky J, et al. Upregulation of endothelial nitric oxide synthase by HMG CoA reductase inhibitors. Circulation 1998:97:1129-35.

36 Feron O, Dessy C, Desager JP, et al. Hydroxy-methylglutaryl-coenzyme A reductase inhibition promotes endothelial nitric oxide synthase activation through a decrease in caveolin abundance. Circulation 2001;103:113-8.

37 Hernandez-Perera O, Perez-Sala D, Navarro-Antolin J, et al. Effects of the 3hydroxy-3-methylglutaryl-CoA reductase inhibitors, atorvastatin and simvastatin, on the expression of endothelin-1 and endothelial nitric oxide synthase in vascular endothelial cells. J Clin Invest 1998;101:2711-9. 
38 Landmesser U, Bahlmann F, Mueller $M$, et al. Simvastatin versus ezetimibe: pleiotropic and lipid-lowering effects on endothelial function in humans. Circulation 2005;111:2356-63.

39 Levin ER. Endothelins. N Engl J Med 1995;333:356-63.

40 Parker JD, Thiessen JJ. Increased endothelin-1 production in patients with chronic heart failure. Am J Physiol Heart Circ Physiol 2004;286:H1141-5.

41 Rademaker MT, Charles CJ, Espiner EA, et al. Combined inhibition of angiotensin II and endothelin suppresses the brain natriuretic peptide response to developing heart failure. Clin Sci (Lond) 2004;106:569-76.

42 Wilkins MR, Redondo J, Brown LA. The natriuretic-peptide family. Lancet 1997;349:1307-10

43 Chen HH, Burnett JC Jr. C-type natriuretic peptide: the endothelial component of the natriuretic peptide system. J Cardiovasc Pharmacol 1998;32(Suppl 3):S22-8.

44 Chun TH, Itoh $\mathrm{H}$, Ogawa $\mathrm{Y}$, et al. Shear stress augments expression of C-type natriuretic peptide and adrenomedullin. Hypertension 1997; 29:1296-302.

45 Totsune K, Takahashi K, Murakami O, et al. Elevated plasma C-type natriuretic peptide concentrations in patients with chronic renal failure. Clin Sci (Lond) 1994;87:319-22.
46 Rauchhaus M, Clark AL, Doehner W, et al. The relationship between cholesterol and survival in patients with chronic heart failure. J Am Coll Cardiol 2003;42:1933-40.

47 Folkers K, Langsjoen P, Willis R, et al. Lovastatin decreases coenzyme Q levels in humans. Proc Natl Acad Sci USA 1990;87:8931-4.

48 Mortensen SA Vadhanavikit S, Folkers K. Deficiency of coenzyme Q10 in myocardial failure. Drugs Exp Clin Res 1984;10:497-502.

49 Strey CH, Young JM, Molyneux SL, et al. Endothelium-ameliorating effects of statin therapy and coenzyme Q10 reductions in chronic heart failure. Atherosclerosis 2005;179:201-6.

50 Mozaffarian D, Nye R, Levy WC. Statin therapy is associated with lower mortality among patients with severe heart failure. Am J Cardiol 2004;93:1124-9.

51 Horwich TB, MacLellan WR, Fonarow GC. Statin therapy is associated with improved survival in ischemic and non-ischemic heart failure. J Am Coll Cardiol 2004;43:642-8

52 Sola S, Mir MQ, Rajagopalan S, et al. Statin therapy is associated with improved cardiovascular outcomes and levels of inflammatory markers in patients with heart failure. J Card Fail 2005;11:607-12.

53 Fukuta $\mathrm{H}$, Sane DC, Brucks S, et al. Statin therapy may be associated with lower mortality in patients with diastolic heart failure: a preliminary report. Circulation 2005; 112:357-63.

\section{IMAGES IN CARDIOLOGY}

\section{Sign of the times}

A 53-year-old man presented with angina of effort in December 2001. The intermediate artery (INT) was stented with a $2.75 \times 15 \mathrm{~mm}$ long Penta stent, the diagonal artery (DGl) with a $2.5 \times 15 \mathrm{~mm}$ long Carbostent, and the occluded obtuse marginal branch of the circumflex (OMCX) with a $2.75 \times 18 \mathrm{~mm}$ long Penta stent. Two months later, the distal circumflex bifurcation lesion was stented with a $2.5 \times 18 \mathrm{~mm}$ long Pixel and a $2.0 \times 18 \mathrm{~mm}$ long Pixel stent in T-stenting fashion (LCX-BF). In November 2002, the right coronary artery (RCA) was treated with a series of three overlapping stents: a $3.5 \times 33 \mathrm{~mm}$ long Zeta proximally, a $3.5 \times 33 \mathrm{~mm}$ long Zeta in the mid-third, and a $3.5 \times 18 \mathrm{~mm}$ long Zeta more distally. In October 2004 , a $2.75 \times 28 \mathrm{~mm}$ Cypher Select stent was placed to a severe stenosis in the mid-third of the OMCX and in June 2005 after an doi: $10.1136 /$ hrt.2005.084152

intracoronary ultrasound study, a $3.0 \times 23 \mathrm{~mm}$ Cypher Select was placed in the proximal left anterior descending artery (LAD). Panels A and B show the 10 implanted stents in the left lateral and right anterior oblique projections respectively.

Occurrence of so many lesions in this man was almost certainly related to his hypercholesterolaemia and his intolerance of all lipid lowering agents because of myalgia and myositis. It is unusual to see so many stents in multiple coronary arteries and their branches in a single individual, but for interventionists it is perhaps a "sign of the times".

D R Ramsdale K A Ramsdale david.ramsdale@ctc.nhs.uk

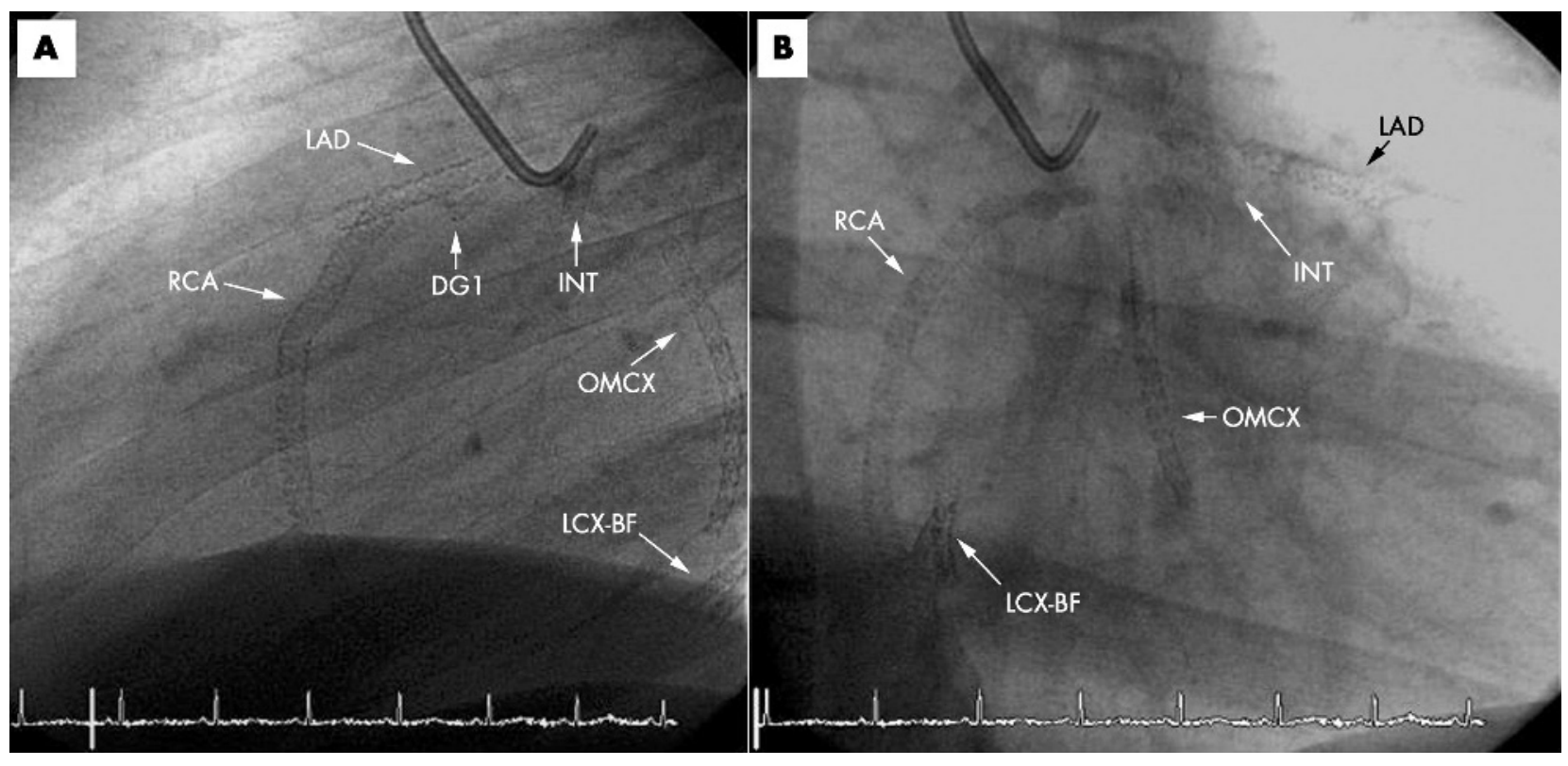

